\title{
Model Sistem Informasi Kampung (Si Kampung) Untuk Penanggulangan Awal Kebakaran Hutan (Studi Kasus Kabupaten Rokan Hulu-Riau)
}

\author{
Hendri Maradona, Kiki Yasdomi, Agung Setiawan, Mi'Rajul Rifqi, Dona \\ Fakultas Ilmu Komputer, Sistem Informasi, Universitas Pasir Pangaraian, Riau, Indonesia \\ Email: ${ }^{1}$ hendrimaradonapakpahan@gmail.com, ${ }^{2}$ kikiyasdomi@gmail.com, ${ }^{3}$ agung.setiawan73@gmail.com \\ 4mirajulrifki@gmail.com, ${ }^{5}$ dona201804@gmail.com
}

\begin{abstract}
Abstrak-Kebakaran hutan di wilayah propinsi Riau telah terjadi setiap tahun dan terus berulang hingga kini. Banyak warga masyarakat yang enggan melaporkan kepada aparat desa, karena jarak yang jauh antara rumah dengan kantor desa. Kondisi masyarakat di kabupaten Rokan hulu, sebagian besar masyarakat dan aparat desa sudah menggunakan smartphone sebagai media komunikasi. Untuk memaksimalkan penggunaan smartphone masyarakat dan aparat desa, maka perlu dibuatkan aplikasi sistem informasi kampung (SI Kampung) sebagai media penghubung, sehingga dapak positif dibuatkan aplikasi SI kampung antara lain meningkatkan harmonisasi antara aparat desa dengan masyarakat, meningkatkan pelayanan kepada masyarakat, meningkatkan peran serta masyarakat, meningkatkan kehidupan demokrasi masyarakat dan mendorong pemberdayaan masyarakat.
\end{abstract}

Kata Kunci: Smartphone, Android, Sistem Informasi, SI Kampung

\begin{abstract}
Forest fires in the Riau province have occurred every year and continue to this day. Many people are reluctant to report to village officials, because of the long distance between community homes and village offices. The condition of the community in Rokan Hulu Regency, most of the community and village officials have used smartphones as a communication medium. To increase the smartphone use of the community and village officials, it is necessary to make an application Sistem Infomasi Kampung (SI Kampung) as a liaison media, so that the positive impact of making the application SI Kampung includes increasing harmonization between village officials and the community, improving service to the community, increasing community participation, improving lives community democracy and encourage community empowerment.
\end{abstract}

Keywords: Smartphone, Android, Information System, SI Kampung

\section{PENDAHULUAN}

Indonesia merupakan salah satu negara kepulauan terbesar di dunia, terdiri lebih dari 13.000 pulau besar dan kecil dengan keberagaman hayati yang terkandung didalamnya. Kekayaan hayati di Indonesia yang besar terkenal sebagai salah satu kekayaan dunia harus selalu dijaga dan dilestarikan. Salah satu kekayaan hayati hutan di Indonesia sebagai kekayaan dunia yang harus selalu dijaga dan dilestarikan adalah harimau dan badak Sumatera. Perkembangan penduduk yang terus bertambah dengan tidak diimbanginya ketersediaan lapangan pekerjaan yang memadai, banyak lahan hutan berubah fungsi menjadi lahan perkebunan masyarakat. Pembukaan lahan perkebunan di Indonesia banyak dilakukan secara konvensional, yaitu melakukan pembakaran lahan.

Kondisi tanah di propinsi Riau sebagian besar adalah lahan gambut dan berakibat sulit dipadamkan saat terjadi kebakaran, terutama jika kondisi kebakaran sudah besar dan menyebar. Dengan kondisi lahan gambut, kebakaran hutan berdampak lebih luas dengan adanya kabut asap yang sulit untuk diatasi, sehingga menjadi bencana nasional. Kondisi cuaca pada musim kemarau, dampak kebakaran hutan menjadi lebih parah dan berdampak kesemua aspek kehidupan masyarakat dan hewan di hutan. Banyak warga masyarakat hendak memberitahukan adanya kebakaran lahan, namun terkendala dengan jauhnya jarak antara warga dengan aparat desa dan instansi yang terkait, seperti badan penanggulangan bencana daerah sebagainya. Selain itu kurangnya informasi nomor telpon desa yang dapat dihubungi, sehingga aparat desa baru mengetahui adanya kebakaran setelah api besar dan sulit padam disebabkan sebagian besar daerah Riau. Standar Pelayanan Minimal adalah ketentuan mengenai jenis dan mutu Pelayanan Dasar yang merupakan Urusan Pemerintahan Wajib yang berhak diperoleh setiap warga negara secara minimal [1].

Informasi yang baik dari aparat desa kepada masyarakat, sangat dibutuhkan untuk memberikan edukasi masyarakat tentang bahaya kebakaran lahan dan informasi penting lainnya yang berhubungan dengan masyarakat. Tujuan penelitian ini adalah untuk mendapatkan gambaran tentang rancangan Sistem Informasi Kampung (SI Kampung). Sistem informasi pada sebuah perusahaan harus dikelola dengan baik dan benar, sehingga menghasilkan informasi yang cepat, tepat dan akurat. Untuk menghasilkan informasi tersebut, diperlukan sebuah mesin yang dapat membantu suatu sistem informasi, yaitu komputer. Sistem adalah sekelompok elemen-elemen yang terintegrasi dengan maksud untuk mencapai suatu tujuan[2], sedangkan informasi merupakan salah satu sumber daya yang tersedia bagi manajer [3]. Jadi sistem informasi merupakan elemen yang saling berintegrasi untuk menyediakan sumber daya informasi bagi seorang manajer. Dengan perkembangan teknologi dan kebutuhan yang kompleks, maka sistem informasi tidak saja digunakan oleh manajer tetapi digunakan oleh orang lain yang sebagai media informas.

that there will always be an implementation phase and an operations phase. The analysis phase focuses on 
understanding the needs of the organization. The design phase focuses on designing the physical aspects of a system to support the needs of the organization[4].

Banyak proyek gagal karena implementasi sistem dikejar tanpa memahami alasan sistem di pertama tempat. Konsep ini setara dengan membeli kayu untuk rumah baru bahkan tanpa mendiskusikan ukuran atau gaya struktur yang diperlukan.Sementara tidak ada yang akan memulai proyek rumah dengan membeli kayu tanpa perencanaan, banyak proyek TI telah diprakarsai oleh pembelian perangkat lunak atau perangkat keras tanpa sepenuhnya mempertimbangkan kebutuhan organisasi.

\section{METODE PENELITIAN}

Untuk melaksanakan penelitian, digunakan cara mendatangi dan melakukan wawancara kepada sejumlah masyarakat dan aparat desa untuk mengetahui kebutuhan sistem yang akan digunakan. Setelah melalukan wawancara, maka selanjutnya dilakukan langkah-langkah pembuatan penelitian, dengan langkah-langkah sebagai berikut :

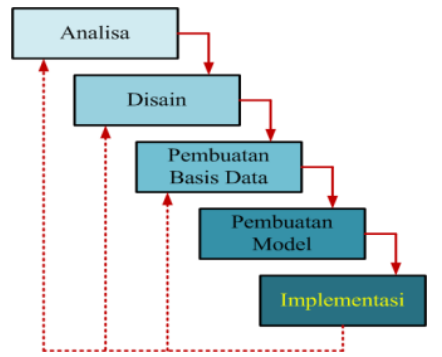

Gambar 1. Metodologi Penelitian

\section{HASIL DAN PEMBAHASAN}

\subsection{Analisa}

Kendala dari kebakaran hutan di propinsi Riau, adalah sulitnya menghubungi aparat desa jika terjadi kebakaran lahan, hal ini disebabkan karena jauhnya jarak antara rumah warga dengan kantor desa akibat dari lahan perkebunan yang luas.

Analisa dari penelitian membutuhkan sebuah model untuk menghubungkan antara masyarakat dengan aparat desa. Pembuatan model didukung oleh teknologi smartphone dengan sistem operasi android, karena sebagian besar masyarakat dan hampir seluruh aparat desa sudah mempunyai smartphone untuk alat komunikasi.

The question of rigor and relevance is particularly important for areas like Information Systems Analysis and Design (IS A\&D). Moreover, the relation of IS A\&D with other IT domains such as software engineering, business processes, and enterprise architectures is not clear and widely accepted at all.[5]

Hasil analisa dibutuhkan sebuah model Sistem Informasi Kampung (SI Kampung) dengan langkah sebagai berikut:

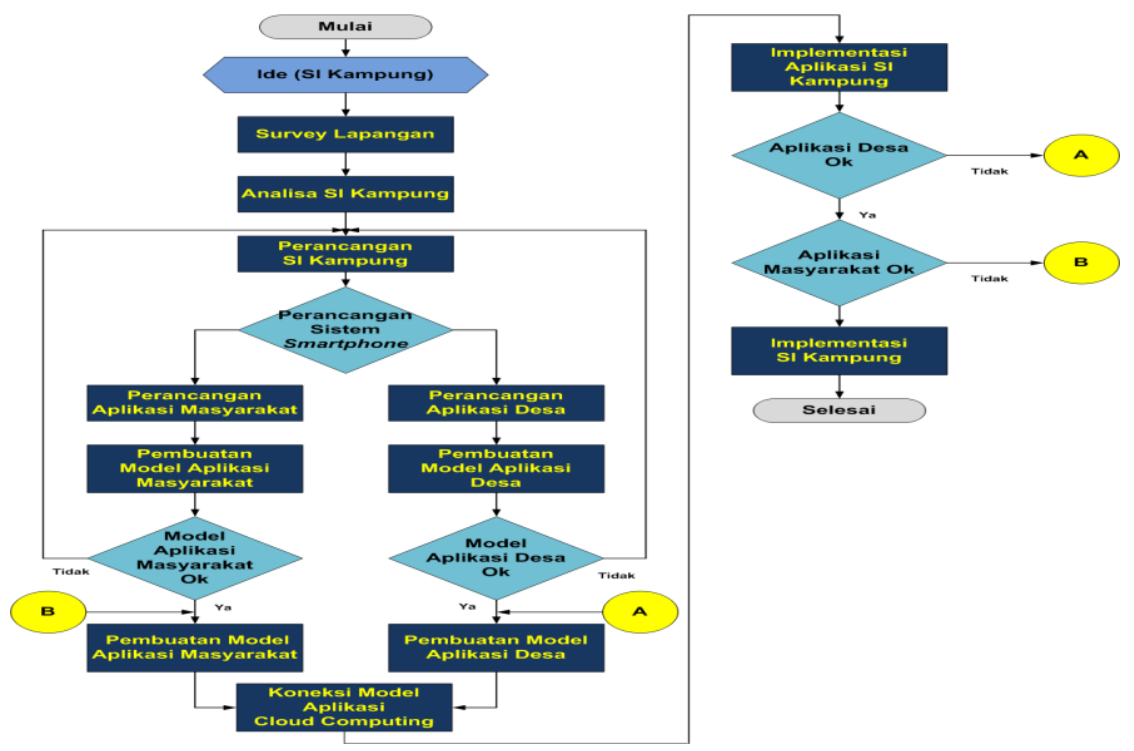

Gambar 2. Alur Pembuatan Model SI Kampung 1 


\subsection{Disain}

Consistent use of the model presented by the platformwas ensured in three ways. First, a policy document was kept by the editors, and updated as specific issues were encountered. Second, the different types of events tracked by the platform were kept to a minimum to allow for an accurate representation of the parliamentary process. In general, we found that users with a small amount of experience with the platform would use themodel in consistent ways because the platform presented them with obvious choices in most situations and required them to make relatively few decisions about how the model would be used. Two to three days of training have proved sufficient with a variety of advanced undergraduate and graduate students. Third, we designed the user interface to force users to capture the sources from which they were working in standard ways, usually by automatically validating the input and requiring active choices within the dialogue boxes presented to users, rather than offering default selections[6]

Disain dari penelitian ini menghasilkan sebuah alur kebutuhan dari SI Kampung. Dalam pembuatan SI kampung dibutuhkan pelaku dari SI Kampung, yaitu masyarakat, aparat desa dan instansi terkait, seperti badan penanggualangan bencana daerah, aparat kepolisan, TNI dan aparat yang lain yang dibutuhkan untuk menanggulangi kebakaran hutan.

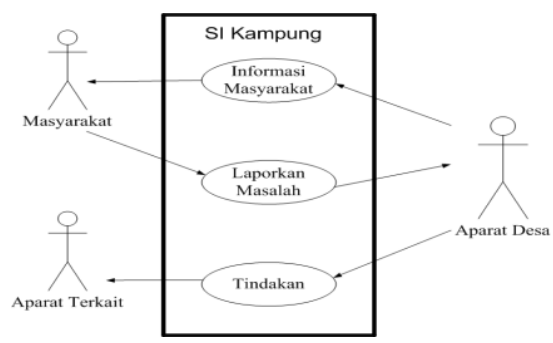

Gambar 3. Use Case SI Kampung

\subsection{Pembuatan Basis Data}

Pembuatan basis data dalam penelitian ini digunakan untuk menyimpan data sebagai bahan untuk pembutaan informasi. Dalam penelitian ini menggunakan aplikasi basis data MySql dan di simpan dalam cloud computing agar dapat digunakan melalui smartphone. Penggunaan aplikasi MySql, karena aplikasi ini tidak berbayar dan banyak penyedia cloud computing hanya menyediakan fasilitas dengan teknologi MySql.

\section{4 implementasi}

Model aplikasi SI Kampung yang telah dibuat menggunakan dua aplikasi yang digunakan oleh masyarakat dan aparat desa, perlu untuk diimplementasikan. Implementasi dilakukan dengan dua langkah, yaitu :

1. Pemasangan atau instalasi aplikasi

Pemasangan atau instalasi pada aplikasi ini dilakukan dengan instalasi di smartphone aparat desa dan smartphone masyarakat. Lakukan ujicoba hingga tercapai aplikasi yang terbebas dari kesalahan. Setelah benar dan bebas dari kesalahan, selanjutnya simpan aplikasi ke web desa atau play store agar dapat di download oleh masyarakat.

2. Pelatihan kepada masyarakat

Untuk memudahkan penggunaan di masyarakat, maka dilakukan sosialisasi dan pelatihan kepada masyarakat. Pembuatan model SI kampung menggunakan teknologi smartphone sebagai media penghubung anatara masyarakat dengan aparat desa. Dalam pembuatan aplikasi ini menggunakan aplikasi eclipse sebagai perangkat lunak berbasis android, sehingga didapatkan rancangan sebagai berikut :

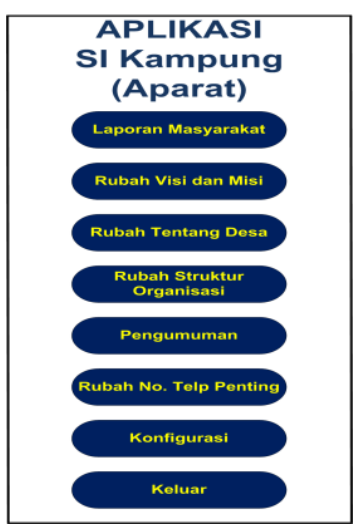

Gambar 5. Menu Smartphone SI Kampung untuk Desa 


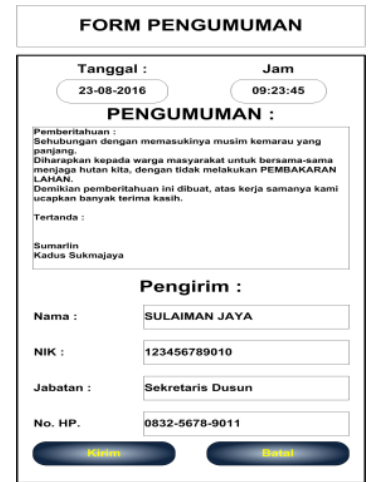

Gambar 6. Form Smartphone Pengumuman Desa SI Kampung

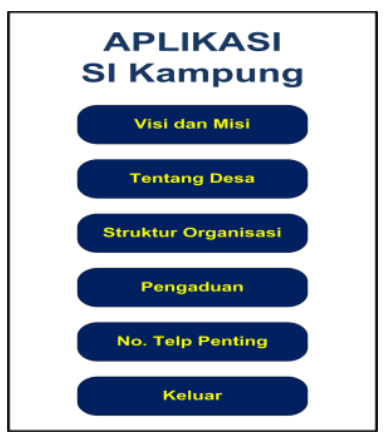

Gambar 7. Menu Smartphone SI Kampung untuk Masyarat

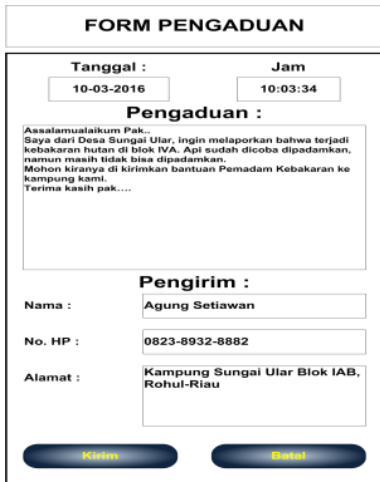

Gambar 8. Form Smartphone Pengaduan SI Kampung untuk Masyarat

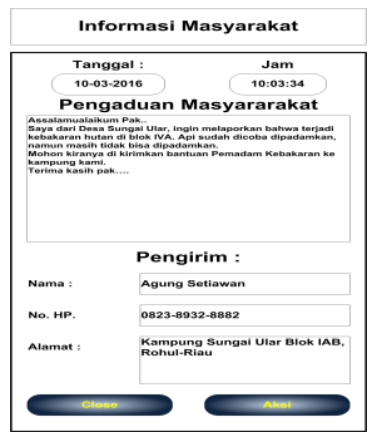

Gambar 9. Form Smartphone SI Kampung dari Masyarakat kepada Desa

\section{KESIMPULAN}

Dari pemaparan di atas, ada beberapa masalah yang harus segera dipecahkan, antara lain :

1. Masyarakat sulit untuk mengadukan masalah yang terjadi atau memberikan masukan kepada kepala desa atau aparat desa.

2. Keterbatasan jumlah aparat desa berdampak penyampaian informasi atau penyuluhan yang terhambat karena jarak yang jauh dan jalan berlumpur jika musim penghujan.

3. Penggunaan smartphone yang belum optimal dengan hanya untuk telpon dan SMS saja, dapat ditingkatkan fungsinya menjadi alat untuk berinteraksi langsung dengan kepala desa dan aparat desa, sehingga tercipta sinergi yang baik antara aparat desa dengan masyarakat.

Sehingga dengan pembuatan aplikasi Sistem Informasi Kampung (SI Kampung) ini akan dihasilkan dampak positif bagi masyarakat maupun aparat desa, sebagai berikut :

1. Meningkatkan harmonisasi antara aparat desa dengan masyarakat.

2. Meningkatkan pelayanan kepada masyarakat.

3. Meningkatkan peran serta masyarakat.

4. Meningkatkan kehidupan demokrasi masyarakat.

5. Mendorong pemberdayaan masyarakat.

\section{REFERENCES}

[1] Pemerintah Republik Indonesia, "Undang-Undang Republik Indonesia Nomor 23 tahun 2014 tentang Pemerintahan Daerah," Kementeri. Sekr. Negara RI, 2014, doi: 10.1017/CBO9781107415324.004.

[2] A. Setiawan, J. Tuanku, T. Kumu, D. Rambah, K. R. Hilir, and K. Rokan Hulu, "Pengaruh Kinerja SDM Dan Efektifitas CBIS Terhadap Daya Saing,” Riau J. Comput. Sci., 2016.

[3] A. Setiawan, K. Yasdomi, U. Pasir Pengairan Jl Tuanku Tambusai Kumu, D. Rambah, K. Rambah Hilir, and K. Rokan Hulu, "Analisa dan Perancangan Sistem Informasi Penggajian untuk Meningkatkan Efisiensi Karyawan (Studi kasus pada PT. Pabrik Obat Indonesia/POI)," Riau J. Comput. Sci., 2016.

[4] R. S, "System Analysis and Design," J. Inf. Technol. Softw. Eng., 2012, doi: 10.4172/2165-7866.s8-e001.

[5] M. Fotache, G. Olaru, and V. Iacoban, "Information Systems Analysts and Designers. Academic/Research Supply vs Market Demand," Procedia Econ. Financ., 2015, doi: 10.1016/s2212-5671(15)00070-2.

[6] N. Cole, A. Abdul-Rahman, and G. Mallon, "A framework for modelling and visualizing the US Constitutional Convention of 1787," Int. J. Digit. Libr., 2018, doi: 10.1007/s00799-018-0263-9. 